larger of these is the gigantic Indian Rhinoceros (R. unicornis), many specimens of which have been brought to this country, and a very fine male example of which is living in the Regent's Park Gardens. In it the skin, which is immensely thick, is thrown into massive folds or shields, making the animal appear as if clad in armourplating. Each shield is thickly studded with nearly circular slightly-raised tubercles, which look very much like the heads of innumerable bolts intended to strengthen and retain the shield in position. The folds that surround the neck, where it joins the head, are very ample, producing the appearance of the now so fashionable ruff, somewhat modified. According to the observations of the late Mr. Edward Blyth, the Indian Rhinoceros is found only at the foot of the Himalayan hills, and in the province of Assam, along the valley of the Brahmapootra.

The second species of one-horned Rhinoceros is generally called the Javan Rhinoceros (R. sondaicus). It is found in Java, and in the country stretching from $\mathrm{Ma}$ lacca up through Burmah to Assam. It is considerably smaller than the Indian species; the shields are not so strongly marked, and are not arranged in an exactly similar manner, the gluteal shield not being completely divided into two by a transverse fold situated half-way down it ; and the middle neck fold, instead of running backwards on each side before it reaches the spine, crosses the middle line, and so divides off a saddleshaped shield, which is median, and as deep from before backwards as from side to side. The fold which surrounds the neck is also much less significant, and the head is narrower and less formidable in aspect. The tuberculation of the shields is more slightly marked, and each tubercle is proportionately smaller in diameter.

It is a specimen of this Javan Rhinoceros ( $R$. sondaicus), a nearly full-grown male from Java itself, which the Zoological Society has succeeded in purchasing, and which is now exhibited in the same house as the Indian species, so that every opportunity is at last afforded for a more minute study of the differences which will most probably be found to distinguish the two species.

The other species of Asiatic Rhinoceroses, namely, the Sumatran Rhinoceros ( $R$. sumatranus), and the Hairy. eared Rhinoceros (R. lasiotis), are both two-horned, and have been divided off as a separate genus, that of Ceratorhinus, by Dr. J. E. Gray. The skin is not divided into shields, and is thinner than in the one-horned species. The type specimen of the Hairy-eared Rhinoceros, the only example known, is now living in the Zoological Gardens. About a year ago the Sumatran animal was also represented, and rumour says that the gap caused by its loss will not be long unfilled.

\section{NEIL ARNOTT, M.D., F.R.S.}

$\mathrm{W} E$ have this week to record the death of this well-known man of science, which took place at his residence in Cumberland Terrace, Regent's Park, on the 2nd inst. He was born at Arbroath in May 1788 , and had consequently reached his eighty-sixth year.

While Neil was yet young his father died, and the family removed to Aberdeen. Neil went to the Aberdeen Grammar School, being there with Lord Byron, and succeeded so well in the one thing then taught, Latin, that he gained a bursary by a competition in Marischal College, which he entered in I80I. In his third year he came under Patrick Copeland, Professor of Natural Philosophy, renowned for his admirable course of lectures, and especially for his power of experimental illustration. Arnott was one of Copeland's best pupils, and afterwards turned to full account the careful notes that he had made of the lectures.

He began the study of medicine in Aberdeen, and in 1806 he went to London to prosecute the study.
Young Annote, while his medical education was still incomplete, went aboard an Indiaman, as assistant. surgeon, making the usual voyage of a trading East Indiaman in those days. He was the intellect and soul of the ship, associating with everyone that could learn or teach anything; he was the resource in all serious emer. gencies, of whatever kind.

On his return to England, in $18 \mathrm{I} r$, he settled as a medi cal practitioner in London. He was the chief medical adviser to a colony of French refugees who settled in Camden Town, and also became physician to the French and Spanish Embassies, his fluency in languages serving him in good stead. It was about 1823 that he first turned to account his studies in natural philosophy, by giving in his own house a course of lectures both on the general subject and on its applications to medicine. These lectures formed the basis of the "Physics," the first volume of which appeared in 1837 , and gained for the author an instantaneous and wide-spread reputation. The first edition was sold in a week after being reviewed by the Times. In a few years five editions were exhausted, and the work was translated into all the languages of Europe. The freshness and popular character of his style recommended the book to the general public, and did not prevent its favourable reception by the highest scientific authorities; Herschel and Whewell both gave emphatic testimonies to its accuracy and originality. The author was thenceforth recognised as a man of science and an inventor of no mean order. His practice as a physician was extended, and he became a Fellow of the Royal Society. On the foundation of the University of London in 1836 he was nominated a member of the Senate, and in 1837 he was named Physician Extraordinary to the Queen.

In 1838 he published a treatise on warming and ventilating, and in this he described the stove since called by his name. $\mathrm{He}$ introduced the water-beds, and made many other useful applications of physics to medical and surgical practice. For many years he had withdrawn from medical practice. He had a large circle of friends in and out of the profession. His conversational powers, his large range of scientific knowledge, and his geniality of manner, will be long remembered by those who now regret his loss.

\section{OZONE*}

II.

SOME of the properties of ozone have already been referred to. At the common temperature of the atmosphere, it may be preserved, if dry, for a very long time in sealed tubes, but by slow degrees it becomes changed again into ordinary oxygen. This conversion goes on more rapidly as the temperature is raised, and at $237^{\circ} \mathrm{C}$. it is almost instantaneous ("Phil. Trans." for $1856, p$. 12). The alteration of volume which occurs at the same time has been already sufficiently described. A similar effect to that of heat is produced by several oxides, such as the oxide of silver or the peroxide of manganese, which by contact, or, as it is termed, catalytically, instantly change ozone into ordinary oxygen. Ozone is also destroyed by auitation with water, provided the ozone is in a highly diluted state. But the most interesting fact of this kind is one which I have recently observed, and which I hope to be able to exhibit to the Society. Dry ozone, even if present in such quantities as freely to redden iodide of potassium paper, is readily destroyed by agitating it strongly with glass in fine fragments, although, as we have seen, it may be preserved for an almost indefinite period in sealed glass tubes. This experiment, as it appears to me, forms a new and closer link than any hitherto observed between a purely mechanical action and a chemical change.

Ozone is a powerful oxidising agent. It attacks metallic mercury and silver with great energy, and converts them into oxides. The experiment with mercury is very striking, and is a delicate test for ozone, either in the dry or moist state. A few bubbles

* Ar Address delivered betore the Royal Society of Edinburgh on December $22, x 873$, by Dr. Andrews, LL.D., F.R.S., Honorary Fellow of the Royal Society of Edinburgh. (Continued from p. 349.) 
of oxygen containing not more than $\frac{1}{\sigma} \frac{1}{\sigma} t^{\text {th }}$ part of ozone will alter whoily the physical characters of several pounds of mercury, taking away the lustre and convexity of the metallic surface and causing the mercury to form an adhering mirror to the surface of the glass vessel in which it is contained. If ozone in a diluted state is slowly passed through a tube filled with silver leaf, the metal will be oxidised to the distance of 2 or 3 millimetres, but the oxidation will not proceed further, although the ozone reactions are wholly destroyed. This striking result is due to the catalytic action of the portions of oxide which are first formed. So small is the amount of oxide produced in this case that, in a glass tube through which many litres of electrolytic ozone had been passed, the increase in weight from the formation of oxide only amounted to a scarcely appreciable fraction of a milligramme.

Ozone is absorbed by oil of turpentine, oil of lemon, and other essential oils. These oils have also, like phosphorus, the power of changing oxygen into ozone, while they are slowly oxidising; so that if oil of turpentine is shaken for some time in a flask filled with air or oxygen, the oil will acquire ozone properties

Ozone decomposes a solution of iodide of potassium, liberating the iodine, which may be discovered by is red colour, or its blue compound with starch. If the action is continued sufficiently long, the free iodine disappears from the formation of iodate of potassium and the solution becomes colourless. Reddened litmus paper moistened with a solution of iodide of potassium is turned blue, when exposed to the action of ozone, in consequence of the caustic alkali formed by the decomposition of the salt. In employing this test it will often be found advantageous to remove the free iodine by washing the paper with strong alcohol. This form of the iodide of potassium test has been proposed by Houzeau for the discovery of ozone in the atmosphere. Ozone produces other reactions of a similar character which it will be sufficient here barely to mention. Paper moistened with sulphate of man. ganese becomes brown when exposed to this agent from the formation of the hydrated peroxide. Solutions of thallous oxicle are in like manner converted into the brown peroxide; the black sulphide of lead into the white sulphate, and the yellow ferro. cyanide of potassium into the red salt. The action of ozone on tincture of guaiacum, which it turns blue, was made a subject of special study by Schönbein.

The bleaching properties of ozone are highly characteristic and have attracted a great deal of attention. It deprives indigo of its blue colour, converting it into isatin, and bleaches readily litmus and other vegetable colouring inatters. Attempts have been made to apply this property of ozone in the arts, and particularly to the refining of sugar and the bleaching of linen. It lias been even stated that these and other applications of ozone, as a decolorising or bleaching agent, have been successful; but the results of my inquiries on this point have, I regret to say, been unfavourable, and it remains yet to be seen whether this singular body can be made subservient to the useful purposes of life. For the preparation of ozone on the large scale from ordinary air, a modification of the tube-generator of Siemens has been proposed by Beanes, and is an efficient and powerful instrument.

I will not detain the Society by an account of the history or properties of the problematical body to which Schönbein gave the name of antozone. He considered this body to be oxygen possessing permanently positive properties, while ozone itself he regarded as negative oxygen. Ordinary or inactive oxygen, according to him, is formed by the union of ozone and antozone. These views have not been supported by recent investigations, which leave little doubt that the antozone of Schönbein is identical with the peroxide of hydrogen of Thénard. From ozone the peroxide of hydrogen can be readily distinguished by the solubility of the latter in water.

Soon after the discovery of ozone, Schönbein having observed that the air of the country frequently coloured a delicate ozone test-paper in the same manner as ozone itself, inferred that ozone is a normal constituent of our atmosphere. He concluded that the amount of this body present in the air is different in different localities, and in the same locality at different times, and with great boldness he attempted to connect its presence or absence with the prevalence or rarity of certain catarrhal affections. A new field for investigation was thus opened up, which has been assiduously cultivated by a large and zealous band of observers. Before referring however to their labours, it will be necessary briefly to allude to the present state of our knowledge regarding the existence of ozone in the atmosphere.
Schönbein always maintained that ozone is a constituent of atmospheric air, and his various papers on this subject alone would, if collected, fill a large volume. In his last memoir he observes that the active substance in the air acts in 2 parallel manner on iodide of potassium and sub-oxide of thallium papers, although more slowly on the latter; and that the thallium paper, which has been coloured brown by the air, behaves towards reagents in the same marner as that which has been ex. posed to artificial ozone. From these facts he infers that the active substance in the air is neither peroxide of nitrogen nor sulphuretted hydrogen. He further states that the atmosphase never contains free nitric acid, although nitrate of ammonium in small quantities is frequently present; and tisat neither chlorine nor bromine can be present in the free state in air, on account of their affinity for hydrogen. Houzeau also maintained that the existence of ozone in the air was proved by the alkaline reaction of iodide of potassium paper, which had been decomposed by exposure to the atmosphere. Although experiments and argu. ments of this kind were sufficient to give probability to the view that the active substance in the atmosphere which protuces these reactions is ozone, they were at the same time far from conclusive, and some of the ablest chemists of Europe accordinuly considered the question doubtful, while others attribued the effects observed to the presence of oxidising agents altogether different from ozone. I will only cite on this point the opinion of $M$. Frémy, whose researches in conjunction with $M$. Becquerel on ozone have already been referred to. "Without denying," he remarked at a meeting of the Academy of Sciences in 1865 , "the importance of the indications given by the paper of M. Schönbein, or by that of M. Houzean, I do not find that these reactions demonstrate with sufficient certainty the existence of atmospheric ozone. I am of opinion that the presence of ozone in the air must be established anew by incontestable experiments."

In I867 I made a set of experiments which I had contemplated some years before for the purpose, if possible, of finally settling this important question. The method $I$ proposed was to ascertain whether, in addition to the power of decomposing solutions of iodide of potassium and of certain other salts, the active body in the atmosphere possessed the other properties of ozone, some of which are highly distinctive. The inquiry was a delicate one, in consequence of the very minute quantity of the active body which is present, even under the most favourable conditions, in atmospheric air. The results of this investigation are given in a short note which was published in the "Proceedings of the Royal Society "for 1867 . (I) By passing a stream of atmospheric air, which gave the nsual ierction with iodide of potassium paper, for some hours over the surface of mercury in a $U$-tube, the metal was distinctly oxidised. (2.) The ozone reactions disappeared when the air was passed through a tube containing pellets of dry oxide of manganese. The experiment was continued till 80 litres of air had traversed the manganese tube without producing the slightest discolora tion of a delicate test-paper. (3.) But the crucial experiment was to ascertain whether the active body in the air loses its characteristic properties, or is destroyed, at the same temperature $\left(237^{\circ} \mathrm{C}\right.$. $)$ as ozone. To determine this point, a stream of atmospheric air, which gave strong ozone reactions, was passed through a globular glass vessel (Fig. 5), covered with wire gauze, of 5 litres capacity, and afterwards through a U-tube $I$ metre in lengtb, whose sides were moistened internally with water, while the tubs: itself was kept cool by being immersed in a vessel of cold water. After traversing the globular vessel and the moistened U-tube, the air was blown over a slip of delicate test-paper, in order to ascertain the presence or absence of ozone. When the atmospheric air was drawn through this apparatus at a uniform rate by means of an aspirator raised by clockwork, the iodicie of potassium paper was distinctly reddened in two or three minutes, provided no heat was applied to the glass globe. But on heating the air as it passed throngh the globe, to a temperature of about $260^{\circ} \mathrm{C}$., not the slightest action was produced on the paper, however long the current of air continued to pass. On the other hand, when air free from ozone, but containing traces of chlozine or of the higher oxides of nitrogen, was drawn through the apparatus, the test-papers were equally affected, whether the globe was heated or not. These experiments have since been successfally repeated by Dr. C. Fox.

The identity of the active body in the atmosphere with ozone we may now assume to be established beyond dispute, and the accuracy of Schönbein's views on this subject to be fully con- 
firmed. To determine, however, the actual amount of orone in the atmosphere is a problem of surpassing difficulty, on account of the extremely small proportion in which it exists, even when at a maximum. Its presence can be easily discovered by any of the ordinary iodised starch.papers, or even more readily by white hibulous paper which has been moistened with a dilute solution of iodide of potassium, and allowed to dry spontaneously in a dark room. If a slip of this paper is exposed for five minutes to a current of air, which will be often supplied by the wind, or may be produced by walking briskly, it will be found to have acquired a delicate red tint, if ozone be present even in the smallest quantities. The tint will be best observed by com. paring the slip after exposure with another slip of the same paper which has not been exposed. The action of the diffused light of day on the paper is rarely perceptible after so short an exposure, but this source of error can be easily avoided by enclosing the paper in a hollow cylinder of wood.

Although with the experimental resources now at our command, we can scarcely venture even to estimate the actual amount of ozone at any time present in the atmosphere, yet it may be possible, as Schönbein long ago proposed, by applying a chromatic scale to the indications of the test-papers, to ascertain approximately its relative amount in different localities, and its variations in the same locality. Such estimates must, however, be most uncertain, since the shades of colour produced on testpaper hardly admit of being defined by numbers; and in this particular case they are liable to a special source of error, as there can be little doubt that a large but unknown part of the ozone in

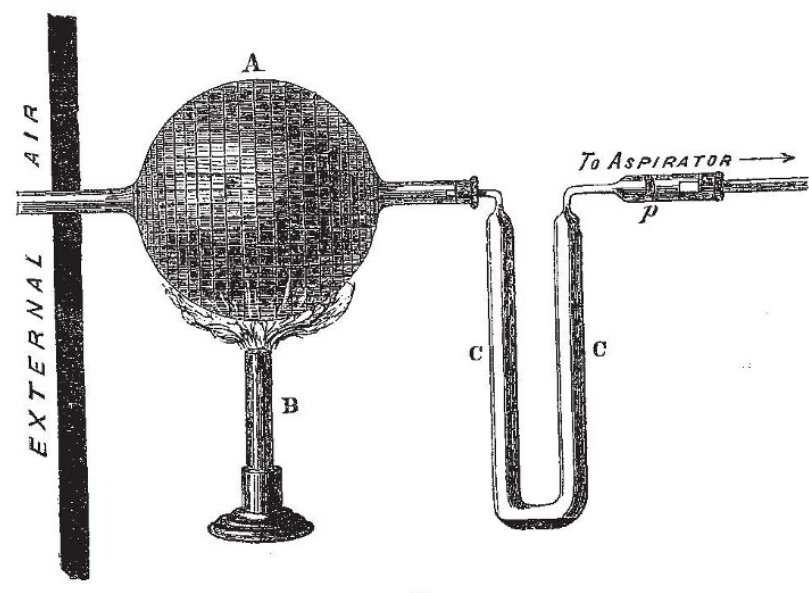

FIG. 5 .

the air which comes into contact with the paper is catalytically destroyed, and produces no chemical effect whatever. At the same time the ozonometer, especially when used with an aspirator, does unquestionably gire indications of value regarding the ozone states of the atmosphere, and till more accurate methods are devised these observations ought certainly to be continued.

Ozone is rarely found in the air of large towns, unless in a suburb when the wind is blowing from the country; and it is only under the rarest and most exceptional conditions that it is found in the air of the largest and best ventilated apartments. It is, in fact, rapidly destroyed by smoke and other impurities which are present in the air of localities where large bodies of men have fixed their habitation, and I have often observed this destructive action extending to a distance of one or two miles from a manufacturing town, even in fine and bright weather.

Ozone is rarely, if ever, absent in fine weather from the air of the country, and it is more abundant, on the whole, in the air of the mountain than of the plain. It is also said to occur in larger quantity near the sea than in inland districts. It has been found to an unusual amount after thunderstorms-a fact which is favourable to the view that the presence of ozone in the atmosphere is due to the action of the free electricity of the latter on the oxygen of the air. The amount of ozone in the air is greater, according to some observers, in winter than in summer, in spring than in autumn; according to others, it is greater in spring and summer than in autumn and winter. As regards the influence of day and night, the observations do not all tell the same tale. Ozone has usually been found more abundantly in the air at night than by day, but some careful observers have found the reverse of this statement to be true.

Schönbein was the first who attempted to connect the fluctuations of atmospheric ozone with the prevalence or absence of epidemic disease ; and since this suggestion was first published, numerous observations have been made in different countries with the view of ascertaining whether there is really any connection between the indications of the ozonometer and the health of a district. It has been asserted, for example, as the result of observation, that an outbreak of cholera is accompanied by a marked diminution of atmospheric ozone; but this statement has been disproved by later and more trustworthy observations. On the whole, I think it may be safely asserted that no cons nection has yet been proved to exist between the amount of ozone in the atmosphere and the occurrence of epidemic or other forms of disease.

The permanent absence of ozone from the air of a locality may, however, be regarded as a proof that we are breathing, if I may venture to use the phrase, adulterated air. Its absence from the air of towns, and of large rooms, even in the country, is probably the chief cause of the difference which every one feels when he breathes the air of a town, or of an apartment however spacious, and afterwards inhales the fresh or ozone-containing air of the open country. It is, indeed, highly probable that many of the most important actions, by which the products of vegetable and animal waste are removed by oxidation from the air, are due to the action of ozone, and could not be effected by ordinary or inactive oxygen. If the amount of ozone in the atmosphere appear too small to produce such large results, we must remember that, from its powerful affinities, ozone is being continually used up, and must, therefore, be constantly renewed.

The physiological action of ozone on the animal system is a subject of interest, and $\mathrm{I}$ am able to state the general results of two independent inquiries - one conducted a few years ago, by Dr. Redfern, in Queen's College, Belfast, the other recently communicated to this Society by Mr. Dewar and Dr. McKen. drick. Dr. Redfern's experiments have not been published, but he has kindly supplied me with the following note on the subject :- "The general results," he says, "I obtained from about forty experiments conducted from May to September, 1857 , to find the effects of oxygen and ozone on different animals, are as follows. The respiration for a very short time of oxygen, containing about $\frac{1}{4 \pi}$ th part of ozone, is certainly fatal to all animals. The same gas, when passed over peroxide of manganese and freed from ozone, is comparatively harmless, even when respired for long periods. Respiration of such a mixture of ozone for thirty seconds kills small animals, some dying after respiring it only fifteen seconds, whilst similar animals will live in good health for months after respiring oxygen alone for thirtyseven hours, the carbonic acid being removed during the experi. ment. Death is not due to the closure of the glottis, for it occurs when a large opening has been made in the trachea. Ozone causes death by producing intense congestion of the lungs with emphysema, and clistention of the right side of the heart with fluid or coagulated blood, frequently attended by convulsions. If ozone be respired in a dilute form, the animals become drowsy and die quietly from coma, the condition of the lungs and heart being the same, except that the emphysema is less marked. Animals which have respired oxygen for more than twelve hours will now and then die suddenly from the formation of coagula in the heart, even after they have appeared in good health for some days."

The following are the conclusions which $\mathrm{Mr}$. Dewar and Dr. McKendrick have deduced from their researches. Inhalation of an atmosphere highly charged with ozone diminishes the number of respirations per minute, and reduces the cardiac pulsations in strength, the temperature of the animal being at the same time lowered from $3^{\circ}$ to $5^{\circ} \mathrm{C}$. After death the blood is found to be in a venous condition. Neither the capillary circu. lation nor the reflex activity of the spinal cord is appreciably affected. The same remark applies to the contractility and workpower of the muscles. Ozone acts on the coloured and colourless corpuscles of the frog like carbonic acid. Ciliary action is not affected by ozonised air or oxygen, but if the layer of liquid be very thin, the cilia are readily destroyed.

The thermal changes which accompany many of the reactions of ozone are well marked, and their investigation, which has been undertaken by Mr. Dewar, promises to yield a valuable addition to our thermo chemical knowledge. 